\title{
Aa. Vv., Balzac et la Chine, «Le Courrier balzacien», nouvelle série, n. $21 / 22$
}

Marco Stupazzoni

\section{(2) OpenEdition}

\section{Journals}

\section{Edizione digitale}

URL: http://journals.openedition.org/studifrancesi/2201

DOI: 10.4000/studifrancesi.2201

ISSN: 2421-5856

\section{Editore}

Rosenberg \& Sellier

\section{Edizione cartacea}

Data di pubblicazione: 1 aprile 2014

Paginazione: 162

ISSN: 0039-2944

\section{Notizia bibliografica digitale}

Marco Stupazzoni, «Aa. Vv., Balzac et la Chine, «Le Courrier balzacien», nouvelle série, n. 21 /22 », Studi Francesi [Online], 172 (LVIII | I) | 2014, online dal 01 avril 2014, consultato il 18 septembre 2020. URL: http://journals.openedition.org/studifrancesi/2201 ; DOI : https://doi.org/10.4000/studifrancesi.2201

Questo documento è stato generato automaticamente il 18 settembre 2020.

\section{(c) (i) (9)}

Studi Francesi è distribuita con Licenza Creative Commons Attribuzione - Non commerciale - Non opere derivate 4.0 Internazionale. 


\title{
Aa. Vv., Balzac et la Chine, «Le Courrier balzacien», nouvelle série,
} n. $21 / 22$

\author{
Marco Stupazzoni
}

\section{NOTIZIA}

Balzac et la Chine, «Le Courrier balzacien», nouvelle série, n. 21 /22, octobre 2012, pp. 82.

1 L'interesse di quest'ultimo fascicolo del «Courrier balzacien» relativo all'anno 2012 risiede nella pubblicazione integrale del denso e, per certi aspetti, atipico compte-rendu di Balzac a proposito dell'album (di 32 litografie) redatto da Auguste Borget con il titolo di: La Chine et les Chinois (Goupil et Vibert, novembre 1842). Il saggio che Balzac pubblicò in quattro feuilletons ne «La Législature» dal $14 \mathrm{al} 18$ ottobre del 1842 è qui riprodotto alle pp. 7-39. Come ci informa Hervé yon ("La Chine et les Chinois". Histoire d'une publication, pp. 5-6), lo scrittore «fut le tout premier à avoir entre les mains une épreuve de l'album d'Auguste Borget» (p. 5) probabilmente fin dal mese di settembre di quello stesso anno.

2 Nel primo dei due studî che Véronique Bur dedica all'articolo balzachiano (Histoire d'un détournement: le compte rendu de "La Chine et les Chinois" par Balzac, pp. 41-56), vengono evidenziate le ragioni per le quali, ancora nel 1842, l'anno in cui vede la luce l'insieme dell'edificio narrativo balzachiano sotto il titolo di La Comédie humaine, Balzac «tient encore à exercer cette mainmise sur la Chine» (p. 42). L'A. intende infatti mostrare «comment Balzac, grâce à une stratégie d'évitement, parvient malgré tout à écrire sur La Chine et les Chinois, tout en détournant son article de son rôle de compte-rendu afin d'en faire un nouveau texte balzacien» (ibid.). Dell'album di Borget, Balzac esalta la straordinaria autenticità di questo racconto di viaggio e prende spunto da questa testimonianza sulla Cina per esprimere, non senza una certa vena polemica, le proprie 
opinioni politiche sul sistema rappresentativo, sulla politica sociale ed economica del governo, sull'ingiustizia e sulla corruzione.

3 Nel secondo studio, V. BUI (Auguste Borget, peintre, voyageur et humaniste, pp. 59-75) traccia un accurato profilo umano ed artistico di Borget che Balzac conobbe per la prima volta nel 1829 grazie a Zulma Carraud e a cui dedicò, nel 1837, La Messe de l'athée.

4 Segnaliamo, in conclusione, l'interessante intervento di Anne-Marie BARON (Juifs et chinois chez Balzac, pp. 76-80) sulla presenza e sul valore degli elementi ebraico e cinese nell'opera balzachiana, oltre alla breve nota, a p. 81, sull'Exposition allestita alla Maison de Balzac ed intitolata: Le Carnaval à Paris (15 novembre 2012-17 février 2013). 